\title{
DNA Microspheres Coated with Bioavailable Polymer as an Efficient Gene Expression Agent in Yeasts
}

\author{
Irena Reytblat, ${ }^{1}$ Anat Lipovsky, ${ }^{1}$ and Aharon Gedanken ${ }^{1,2}$ \\ ${ }^{1}$ Bar-Ilan Institute for Nanotechnology and Advanced Materials, Department of Chemistry, Bar-Ilan University, \\ 52900 Ramat Gan, Israel \\ ${ }^{2}$ Department of Materials Science \& Engineering, National Cheng Kung University, Tainan 70101, Taiwan
}

Correspondence should be addressed to Anat Lipovsky; ecoli2310@yahoo.com

Received 21 September 2015; Revised 18 November 2015; Accepted 26 November 2015

Academic Editor: Abdelwahab Omri

Copyright (C) 2016 Irena Reytblat et al. This is an open access article distributed under the Creative Commons Attribution License, which permits unrestricted use, distribution, and reproduction in any medium, provided the original work is properly cited.

\begin{abstract}
Gene delivery is one of the steps necessary for gene therapy and for genetic modification. However, delivering DNA into cells is challenging due to its negative charge that leads to repulsion by the negative cell membrane. In the current research, DNA spheres with a DNA encoding to a certain gene were coated with bioavailable polymers, polyethylene imine (PEI) and polycaprolactone (PCL), in a short, one-step sonochemical reaction. The polymers were used in order to neutralize the negative charge of the DNA. Our study shows that the DNA nanospheres not only managed to penetrate the cell without causing it any damage, but also expressed the desired gene inside it.
\end{abstract}

\section{Introduction}

Gene delivery remains a challenge. There are several obstacles that have to be overcome for the successful functioning of nucleic acid within a cell. First, the nucleic acid must enter the target cell. As easy as this may sound, this first step is almost the hardest one. The strong negative charge of nucleic acid (DNA/RNA) causes its repulsion by the negative charge of the cell membrane $[1,2]$. Much work has focused, in recent years, on finding ways to enhance the transformation (uptake and incorporation of exogenous genetic material) in yeast. It was found that monovalent cations such as $\mathrm{Na}^{+}, \mathrm{K}^{+}, \mathrm{Rb}^{+}, \mathrm{Cs}^{+}$, and, particularly, $\mathrm{Li}^{+}$, but not divalent cations such as $\mathrm{Ca}^{2+}$ (which was effective for E. coli transformation), enhance the transformation efficiency of $S$. cerevisiae. The reason for the effectiveness of these monovalent cations might be their mild chaotropic effect during the transformation [3]. Mechanical methods such as electroporation and biolistic methods were also developed for enhancing transformation. In the biolistic method, cells can be transformed with DNA-coated metal microprojectiles that are shot into the cells [4]. In the glass bead method, the glass beads cause physical damage, thereby facilitating the entrance of DNA to the cell [5].
Other techniques for transformation include viral vectors or polymers that facilitate the penetration of nucleic acids (NA) into the cell.

During the course of this work, we used positively charged bioavailable polymers for gene delivery. Two polymers, polyethylenimine (PEI) and polycaprolactone (PCL), were chosen to coat the DNA and neutralize the negative charge enabling it to penetrate the cell.

Polyethylenimine (PEI) or polyaziridine is a polymer with repeating units composed of an amine group and two carbon aliphatic $\mathrm{CH}_{2} \mathrm{CH}_{2}$ spacers [6]. The branched PEIs contain primary, secondary, and tertiary amino groups. PEI is produced on industrial scale and serves many applications usually derived from its polycationic character [7]. The branched PEIs are liquids at all molecular weights. PEI was the second polymeric transfection agent discovered [8] after poly-l-lysine. PEI condenses DNA microspheres into positively charged particles, which bind to anionic cell surface residues which are brought into the cell via endocytosis.

In recent years, PCL has received a great deal of attention. It is known to be a biodegradable polymer due to its ester group, which easily undergoes hydrolysis in the living cell. PCL has been shown to be degraded by the action of aerobic 
and anaerobic microorganisms that are widely distributed in various ecosystems. Furthermore, the degradation of high molecular weight PCL was investigated using Penicillium spp. [9].

Polycaprolactone (PCL) is an important polymer due to its mechanical properties, miscibility with a large range of other polymers, and biodegradability [10].

PCL has been approved by the Food and Drug Administration (FDA) for specific applications in the human body and is used, for example, as a drug delivery device. In addition, it has been investigated as a scaffold for tissue repair via tissue engineering [11].

Once inside the cell, protonation of the amines results in an influx of counter-ions and lowering of the osmotic potential. Osmotic swelling results in the burst of the vesicle releasing the polymer-DNA complex (polyplex) into the cytoplasm. If the polyplex unpacks, then the DNA is free to diffuse to the nucleus $[9,10]$.

We used a one-step sonochemical technique to prepare microspheres of DNA and coated sonochemically these microspheres with PEI and PCL for their insertion into cells.

In the last two decades with the progress in nanotechnology, many synthetic methods for fabrication of various kinds of nanomaterials have been developed. Sonochemistry is one of the most efficient techniques for the creation of nanosized compounds including both organic and inorganic NP, as well as nano-/microspheres and core-shell nanostructures [12]. It was first shown by Suslick and Grinstaff that the synthesis of nonaqueous liquid-filled microcapsules and air filled microbubbles can be achieved by ultrasound [12]. It has been shown that micrometer-sized gas- or liquid-filled proteinaceous microspheres can be produced from various kinds of proteins, such as bovine serum albumin (BSA) [11, 13], human serum albumin (HSA) [14], and hemoglobin (HB) [15].

Recently, this technique was extended to encapsulate drugs in bovine serum albumin microspheres and deliver them into cells [16]. The microspherization method was also extended to prepare RNA and DNA hydrophobicsolvent-filled nucleic acid nanospheres [14, 15]. The RNA nanocapsules showed stability for at least one month at room temperature. The DNA nanocapsules produced using ultrasonic waves were stable in a wide range of temperatures, pHs, and DNAase and allow genetic information to be delivered into human U2OS cancer cells and into E. coli competent cells where expression of proteins was successfully achieved [17].

Candida was chosen as a transfection model due to its high prevalence and excellent capability for acquiring resistance.

C. albicans is an important pathogen causing a wide variety of infections, ranging from topical infection (or pharyngeal/vulvovaginal candidiasis) to invasive candidiasis. Over $75 \%$ of women will suffer from a C. albicans infection during their life. C. albicans are the 4th leading cause of nosocomial infections in patients' bloodstreams. This can result in an extremely life-threatening, systemic infection in hospital patients with a mortality rate of $30 \%$ [17].
The number of synthetic antifungal compounds and classes of therapeutic agents available to treat candidiasis has been increasing in recent decades, including polyenes, azoles, purine analogues, and echinocandins. As fungal pathogens are eukaryotes, however, they share some of their biological processes with human cells, which lead to major harmful side effects from the use of antifungal drugs. Furthermore, the increased resistance of pathogens to synthetic agents and the need for cost-effective treatments to manage oral candidiasis have driven the search for novel alternatives in this field [18].

In the current study we report on the successful sonochemical preparation of DNA nanospheres coated by the above-mentioned bioavailable polymers. The DNA nanospheres were able to enter Candida albicans (C. albicans) cells and retained their function as shown by their ability to express the GFP and mCherry genes delivered into the Candida cells.

\section{Results and Discussion}

After the sonochemical reaction, a polydispersed solution was obtained, with microspheres having a wide range of size distribution within $5 \mathrm{~nm}-7 \mu \mathrm{m}$. The size distribution of the DNA spheres coated with polymer in aqueous solution was measured using dynamic light scattering (DLS) as shown in Figure 1.

It was anticipated that small spheres will be easily inserted into the Candida cells; therefore, an effort was made to separate the small spheres and to subject them to further experimentation. This was done using a PVDF syringe filter that has a pore size of $200 \mathrm{~nm}$. The size distribution of the microspheres in Figure 1 is that obtained after the filtration. In spite of the separation efforts larger (than $200 \mathrm{~nm}$ ) capsules were also observed. The larger size can be attributed to partial aggregation of the smaller spheres. Only the filtered, small microspheres were used in the experiments involving living cells.

According to the DLS results, the as-prepared size of DNA - polymer microspheres coated with PEI ranged within $700 \mathrm{~nm}-6500 \mathrm{~nm}$, the average size being $1930 \mathrm{~nm}$. This size was too large for use of the microspheres for insertion into living cells, and therefore the solution was filtered. The size of filtered DNA spheres coated with PEI (DNA_PEI) was $59 \mathrm{~nm}-712 \mathrm{~nm}$, with a calculated average size of $162 \mathrm{~nm}$ (Figure 1(b)). The size of the filtered DNA microspheres coated with PCL (DNA_PCL) was within $5 \mathrm{~nm}-1000 \mathrm{~nm}$, and a bimodal distribution was detected, with average sizes of $7.5 \mathrm{~nm}$ and $102 \mathrm{~nm}$ (Figure 1(c)).

The effect of the PEI and the PCL polymers on the charge of the DNA microspheres was examined by $\zeta$-potential measurements. The negative charge of the pristine DNA capsules was $-50 \mathrm{mV}$ as demonstrated in Figure 2(a). The negative charge on the surface of the DNA sphere indicates that the phosphates of the nucleic acid are facing the outside part of the capsule. To facilitate the penetration into the cells it is necessity to cap the sphere with a material to neutralize the negative charge. Two polymers were chosen for this purpose: PEI and PCL. The figures show that the surface of 


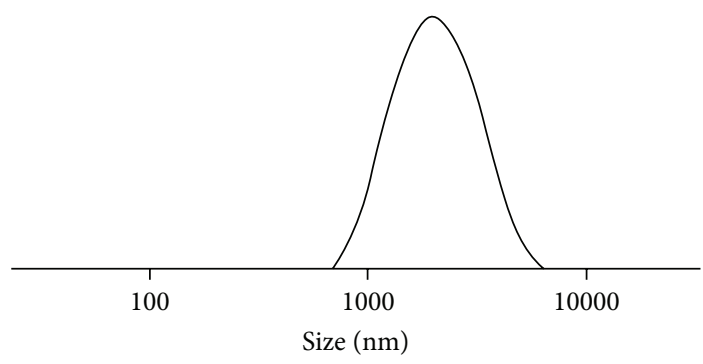

(a)

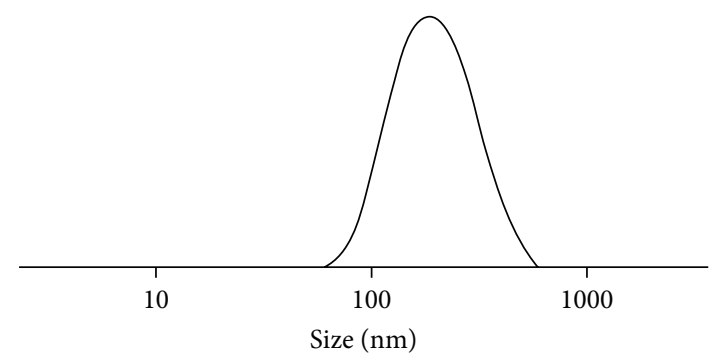

(b)

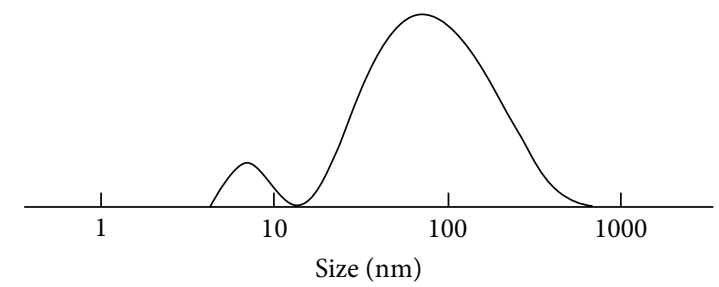

(c)

FIGURE 1: Size measurements for (a) DNA microspheres coated with PEI, (b) filtrated DNA microspheres coated with PEI, and (c) filtrated DNA microspheres coated with PCL.

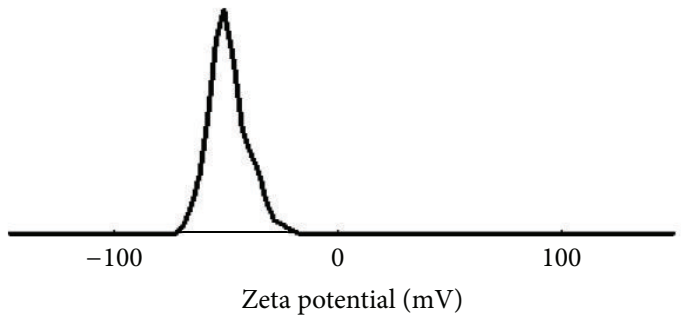

(a)

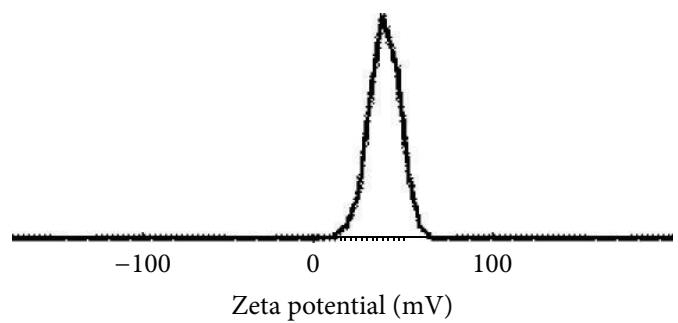

(b)



(c)

FIGURE 2: Zeta potential measurements for (a) DNA microspheres, (b) DNA microspheres coated with PEI, and (c) DNA microspheres coated with PCL.

the DNA microspheres coated with PEI have a positive charge of $32.5 \mathrm{mV}$ (Figure 2(b)), and the surface of microspheres coated with PCL is almost neutral (Figure 2(c)):

\section{GFP filter}

$=$ green fluorescent signal (excitation at $489 \mathrm{~nm}$;

emission at $509 \mathrm{~nm})$.

The next step was to prove the penetration of the prepared DNA microspheres through the Candida cell membrane. For this, FITC labeled microspheres were prepared.

FITC tagged polymers (both PEI and PCL) were used for the preparation of the DNA microspheres. In Figures 3(a) and 3(b) unfiltered DNA microspheres coated with FITC labeled PEI (b) and PCL (a) are presented. The images were obtained using a fluorescence microscope (Apo-Tome, Axioimager Z1, Zeiss).

To study the ability of DNA_PCL and DNA_PEI small microspheres (filtered, $<200 \mathrm{~nm}$ ) to penetrate the Candida membrane and enter the cell, we incubated the cells in the presence of the spheres as described in the experimental section.

After the incubation, the cells were fixed on cover slides and examined using a confocal fluorescence microscope (Olympus-FV1000). Figure 4 exhibits the resultant cells after the incubation with DNA_PCL and DNA_PEI microspheres. 


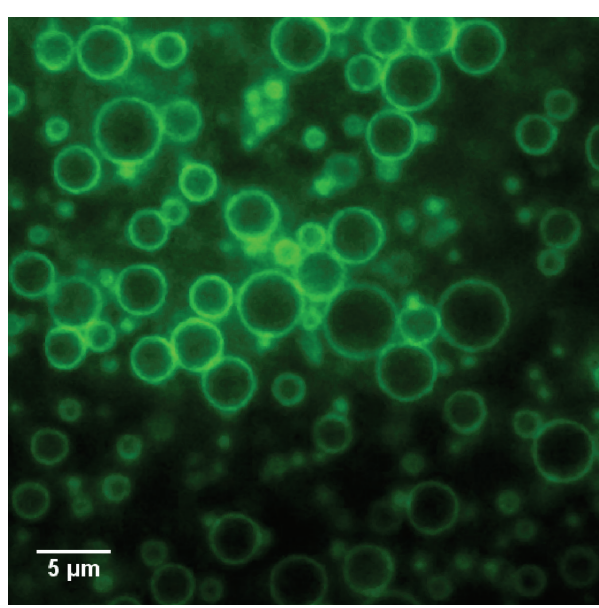

(a)

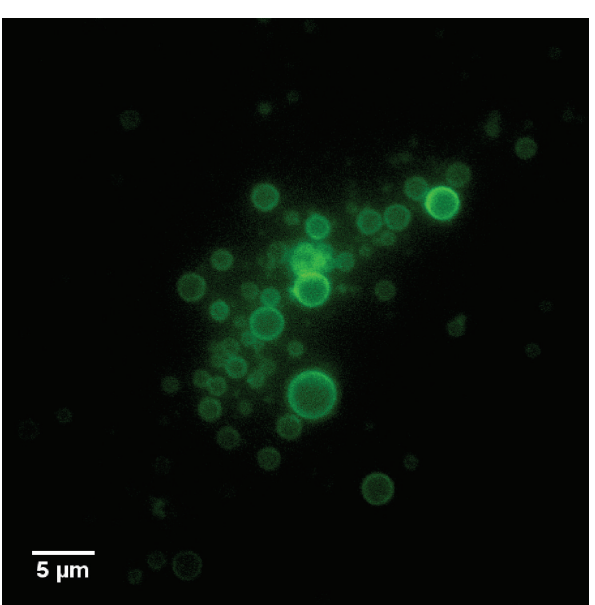

(b)

FIGURE 3: Fluorescent microscopy images of FITC labeled microspheres. (a) DNA microspheres coated with FITC labeled PCL. (b) DNA microspheres coated with FITC labeled PEI.

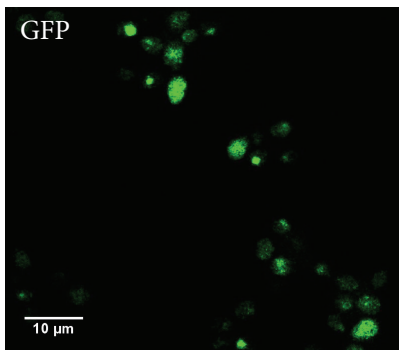

(a)

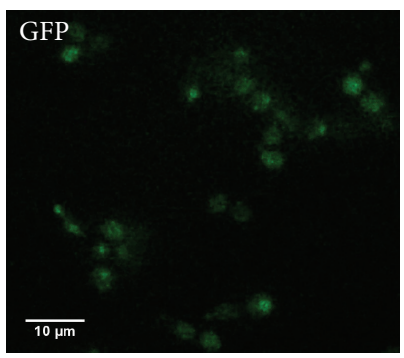

(d)

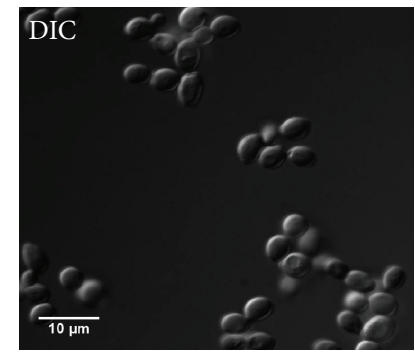

(b)

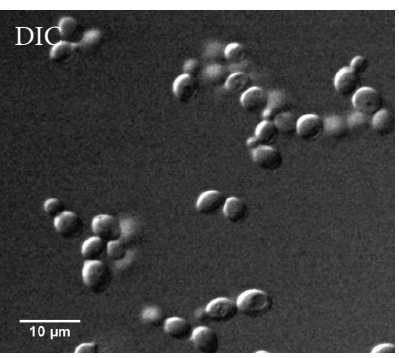

(e)

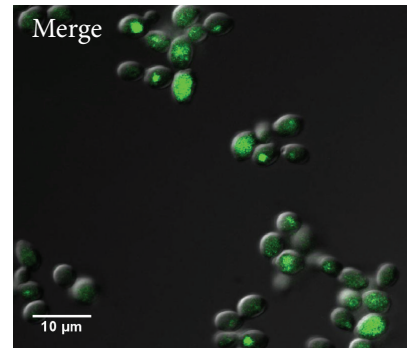

(c)

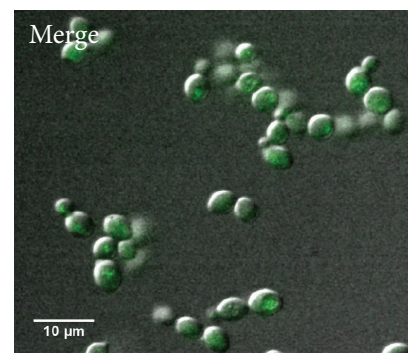

(f)

FIGURE 4: Fluorescent microscopy images of Candida cells after $16 \mathrm{~h}$ incubation with FITC labeled DNA microspheres. (a)-(c) Candida cells after introduction to DNA spheres coated with FITC labeled PEI. (d)-(f) Candida cells after introduction to DNA spheres coated with FITC labeled PCL. (a, d) Green fluorescence mode $\left(\lambda_{\text {exc }} 488 \mathrm{~nm}, \lambda_{\mathrm{em}} 507 \mathrm{~nm}\right.$ filter = green); (b, e) bright-field images (DIC); the merged figures (c, f) represent the data obtained when the two images are combined.

Green fluorescence is observed inside the cells, confirming the presence of the FITC labeled microspheres inside the cytoplasm and their ability to pass through the cell membrane. When comparing DNA_PCL and DNA_PEI microspheres, it was seen that they exhibit comparable penetration capabilities, due to their increased positive charge and thus higher attraction to the cell surface. However, it is important to remember that there is an extremely delicate balance between the higher attraction of the more positively charged particles and their elevated toxicity. Due to its higher positive charge, the PEI caused some cell death in Candida culture; therefore, the PCL microspheres presented the best option due to their optimal charge elevating their attraction and penetration into the cell but not high enough to cause significant toxicity (less than $5 \%$ reduction in cell viability).

As a final step we prepared microspheres employing DNA encoding green fluorescent protein (GFP) or mCherry protein having green and red fluorescence, respectively.

For this purpose, we preferred using DNA_PCL microspheres due to their negligible toxicity. Although PEI is considered biocompatible, it was found to be toxic to Candida at certain concentrations. Therefore, we tested the viability of 


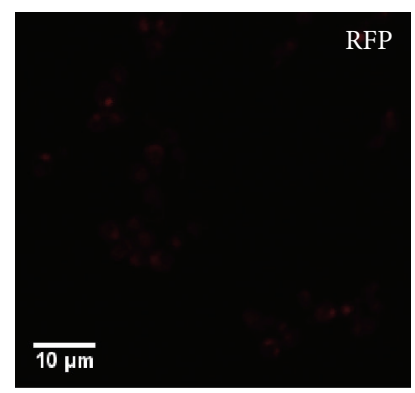

(a)



(d)

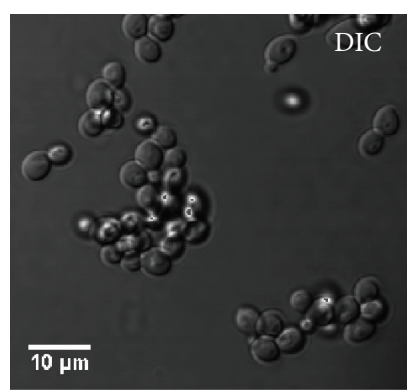

(b)

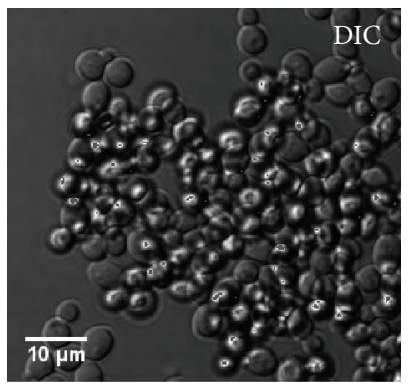

(e)

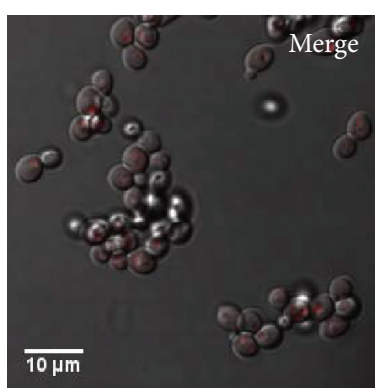

(c)

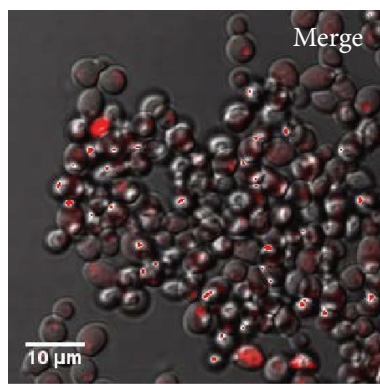

(f)

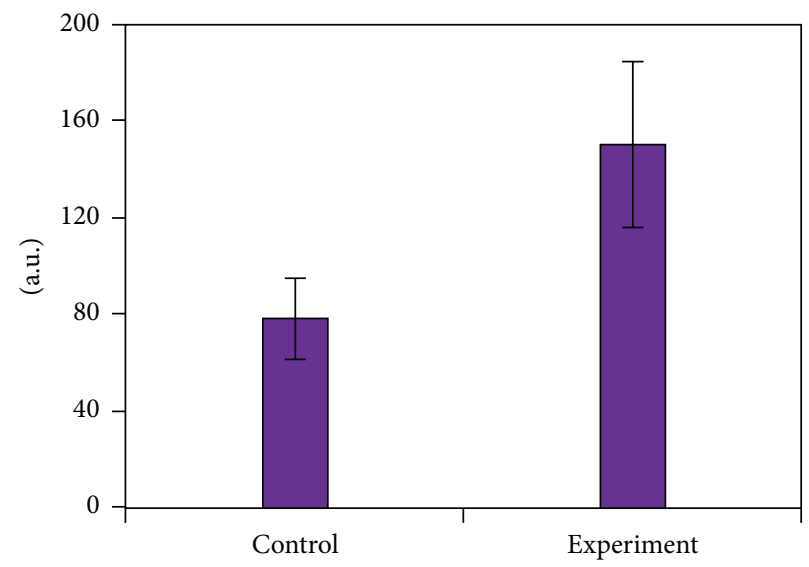

(g)

FIgure 5: Gene expression of the mCherry in Candida. (a)-(c) Control: Candida cells without any exposure to DNA microspheres. (d)-(f) Candida cell after incubation with DNA microspheres encoding to mCherry expression, coated with PCL. (g) Fluorescence calculations of the mCherry expression inside the cells. Red fluorescence (a,d) (rhodamine mode: $\lambda_{\text {exc }}=587 \mathrm{~nm}, \lambda_{\text {em }}=610 \mathrm{~nm}$ ); (b, e) bright-field images (DIC); the merged figures (c, f) represent the data obtained when two filters are used.

C. albicans after incubation with DNA_PCL and DNA_PEI microspheres. DNA_PCL microspheres caused only $5 \%$ cell death while the DNA_PEI microspheres caused the death of about $35 \%$ of the cells.

In Figure 5 the expression of the mCherry protein is shown.

Microspheres prepared from DNA encoding mCherry covered by PCL and containing soy-bean oil were prepared. Without any purification, only after filtration to separate the smallest spheres, the as prepared microspheres were introduced to Candida cells. The cells were incubated in the presence of the microspheres for $16 \mathrm{hr}$, at $37^{\circ} \mathrm{C}$. After the incubation, they were examined using confocal microscopy. Figures 5(a)-5(c) show the control group, that is, Candida cells without any treatment with the microspheres. The observed fluorescence is the autofluorescence of the cells, which is normally observed in living cells. Figures $5(\mathrm{~d})-5$ (f) show the fluorescence of the cells after their treatment with the mCherry encoding microspheres. Figure 5(g) displays a quantitative calculation of the fluorescence in both control and experimental groups, considering the standard deviation of the current experiment. The quantitative calculations were performed by evaluating the fluorescence intensity of the bare cells and of the cells treated by the encoding microspheres. These fluorescence measurements were analyzed with the help of the Imagej program. While the fluorescence of the control group was only 80 a.u., when employing the mCherry encoding microspheres a fluorescence signal of 


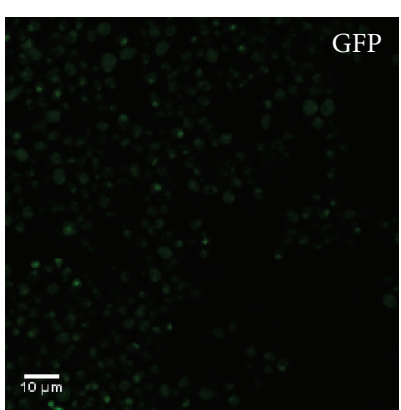

(a)



(d)

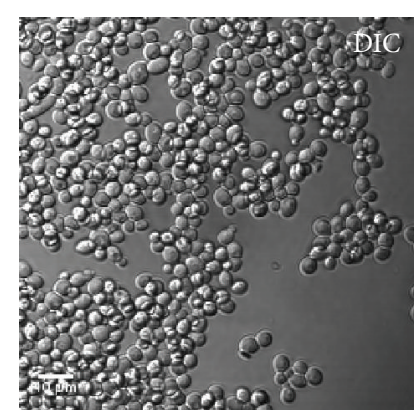

(b)

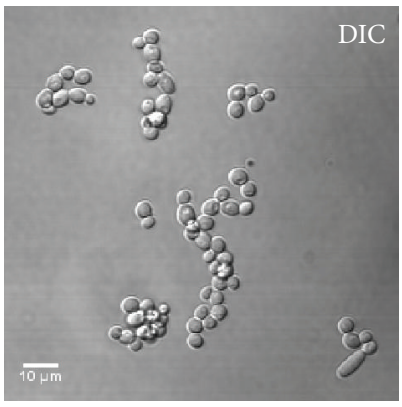

(e)

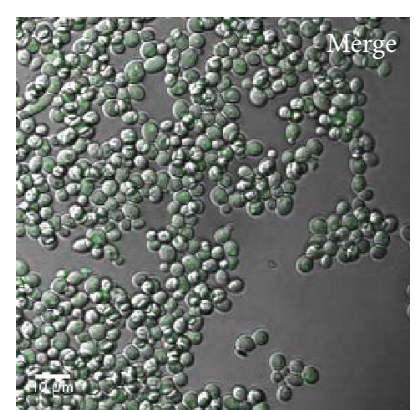

(c)

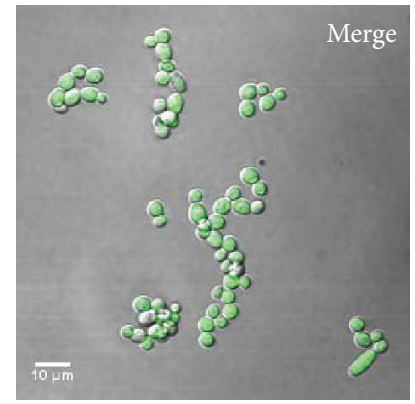

(f)

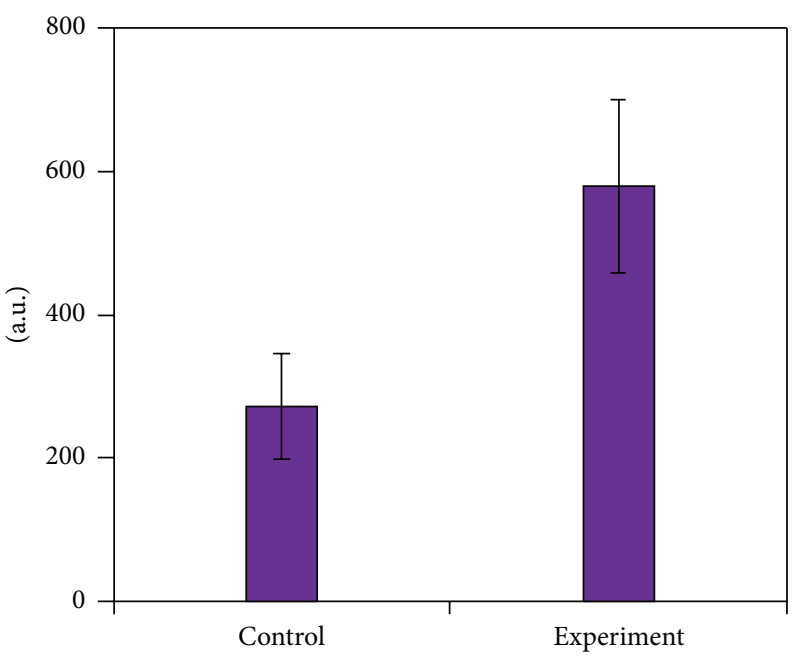

(g)

FIGURE 6: Gene expression of the GFP in Candida. (a)-(c) Control: Candida cells without any exposure to DNA microspheres. (d)-(f) Candida cell after incubation with DNA microspheres encoding to GFP expression, coated with PCL. (g) Fluorescence calculations of the GFP expression inside the cells. (a, d) Green fluorescence mode $\left(\lambda_{\text {exc }} 488 \mathrm{~nm}, \lambda_{\mathrm{em}} 507 \mathrm{~nm}\right.$ filter = green); (b, e) bright-field images (DIC); the merged figures $(c, f)$ represent the data obtained when two filters are used.

more than 160 a.u. was measured. Treating Candida cells with microspheres made of soya oil and water with PEI or PCL but without DNA yielded results similar to the control group shown in Figures 5(a)-5(c), thus refuting any possibility of fluorescence caused by the microspheres and not by the gene encoding DNA. It can be concluded that the level of the fluorescence after treating the cells with the sonochemically prepared microspheres encoding to expression of mCherry is twice higher than that of the control group.
The quantitative calculations were obtained using the Imagej program, after calculating the fluorescence of at least 300 cells.

Figure 6 presents results of another experiment regarding gene expression of GFP. The results show the expression of GFP in Candida cells after treatment by DNA microspheres coated with PCL encoding the green fluorescent protein. Comparing Figures 6(a) and 6(d) shows that the intensity of the fluorescence in the experimental 
group is much higher than the autofluorescence of the Candida cells.

The quantitative calculations given in Figure 6(g) demonstrate that the fluorescence level in the control group was 272 a.u. while the level after the treatment with the GFP encoding microspheres was 580 a.u.

From the results given in Figures 5 and 6, it can be concluded that our sonochemically prepared DNA microspheres can be used for gene expression in living yeast cells.

\section{Experimental Section}

3.1. Preparation of DNA Microspheres Coated by Polymer. DNA spheres, coated with the polymer were generated by using a high-intensity ultrasonic probe (Sonic and Materials, Newtown, CT, VC-600, $20 \mathrm{kHz}, 3 \mathrm{~mm}$ Ti horn, at $32 \%$ amplitude). The volume of the acoustic cell was $10 \mathrm{~mL}$, and the total volume of all the ingredients was $1.67 \mathrm{~mL}$. The ultrasonic transducer delivered an acoustic power of $\approx 26.7 \mathrm{~W} \cdot \mathrm{cm}^{-2}$. The temperature in the reaction cell was initially set to $22^{\circ} \mathrm{C}$. The sonication lasted for $3 \mathrm{~min}$, and the cell was immersed in an ice bath to dissipate any temperature gradients imparted by the acoustic waves.

3.2. Preparation of DNA Microspheres Covered by FITC Labeled Polymer. DNA (lambda DNA, 48,490 base pairs in length, was purchased from "New England Bio Labs" company) and soy-bean oil were used without further purification.

DNA microspheres were prepared by dissolving $4 \mu \mathrm{g}$ DNA in $1 \mathrm{~mL}$ of doubly distilled $\mathrm{H}_{2} \mathrm{O}$, adding $1 \mathrm{gr}$ of PCL and $150 \mu \mathrm{L}$ of FITC stock solution, and then $0.67 \mathrm{~mL}$ soy-bean oil.

Preparation of FITC stock solution: $1 \mathrm{mg}$ FITC was dissolved in $1 \mathrm{~mL}$ ethanol.

For the preparation of DNA microspheres coated by FITC labeled PEI, the DNA was added into a solution of FITC labeled PEI which was prepared in advance $(1 \mathrm{~mL}$ PEI $5 \%$, $75 \mu \mathrm{L}$ of FITC stock solution). Soy-bean oil was added into the aqueous solution, and sonication was activated for 3 minutes.

\subsection{Preparation of DNA Microspheres Encoding to Gene Expression of GFP or mCherry Coated with Polymer}

3.3.1. Preparation of DNA_PCL Encoding Microspheres. $1 \mathrm{gr}$ PCL (purchased from Sigma Aldrich, average $M_{n} 45,000$ ) were added into a DNA aqueous solution, containing $1.5 \mu \mathrm{g}$ DNA (pEGFP-C1 or mCherry-N1; plasmids were amplified using HiPure Plasmid Maxiprep kit (Invitrogen)) dissolved in $1 \mathrm{~mL}$ doubly distilled $\mathrm{H}_{2} \mathrm{O}$. Then, $0.67 \mathrm{~mL}$ soy-bean oil was added into the aqueous solution.

The DNA microspheres were generated by using a highintensity ultrasonic probe (Sonic and Materials, Newtown, CT, VC-600, $20 \mathrm{kHz}, 3 \mathrm{~mm}$ Ti horn, at $32 \%$ amplitude). The volume of the acoustic cell was $10 \mathrm{~mL}$, and the total volume of all the ingredients was $1.67 \mathrm{~mL}$. The ultrasonic transducer delivered an acoustic power of $\approx 26.7 \mathrm{~W} \cdot \mathrm{cm}^{-2}$. The temperature in the reaction cell was initially set at $22^{\circ} \mathrm{C}$.
The sonication lasted for $3 \mathrm{~min}$, and the cell was immersed in an ice bath to dissipate any temperature gradients imparted by the acoustic waves.

The conventional ratio between the aqueous and the organic phases in the preparation of protein microspheres is $3: 2$. This ratio was kept in the preparation of DNA microspheres.

3.3.2. Preparation of DNA_PEI Encoding Microspheres. $1.5 \mu \mathrm{g}$ DNA was added into $1 \mathrm{~mL}$ of $5 \%$ PEI aqueous solution (PEI was purchased from Sigma Aldrich, branched chain polymer, $50 \%$ (w/v) in $\mathrm{H}_{2} \mathrm{O}, \mathrm{Mw} 750,000$ ). Then, $0.67 \mathrm{~mL}$ soy-bean oil was added into the aqueous solution.

Three-minute sonication was performed as described above.

\subsection{Characterization}

3.4.1. Microscopy. For light microscopy, samples were viewed and photographed as wet mounts, using a confocal microscope, Olympus-FV1000, equipped for Nomarski optics. $1 \mathrm{~mL}$ of cell suspension was added dropwise onto a microscope cover-slip covered with polylysine solution $(50 \mu \mathrm{g} / \mathrm{mL})$. After $30 \mathrm{~min}$, the droplet was removed, and $1 \mathrm{~mL}$ PFA $4 \%$ was added to the cover slip for 11-18 min for fixation of the cells. PFA was removed and the slide was washed with saline $(1 \mathrm{~mL}$ saline, 2 times).

3.4.2. DLS. The $\zeta$-potential and the size distribution of microspheres were determined at $25.0 \pm 0.1^{\circ} \mathrm{C}$ using a Malvern zetasizer NS (Malvern Instruments) with an electrophoretic laser Doppler anemometry and photon correlation spectroscopy (PCS), respectively; the experimental solutions were placed into a disposable cuvette and measured as per standard protocol supplied by the manufacturer.

3.4.3. Strains and Growth Conditions. Clinical strain of $C$. albicans (recovered from the bacteriological laboratory of the Meir Hospital, Kfar-Saba, Israel) was used through this study. The strains were routinely inoculated from overnight cultures of C. albicans grown on NA (Nutrient Agar) supplemented with $2 \%$ glucose to obtain fresh culture several colonies which were transferred into $\mathrm{NB}+4 \%$ glucose at an initial optical density (OD) of 0.1 at $660 \mathrm{~nm}$.

Cultures were allowed to grow in a rotary-shaker incubator at $37^{\circ} \mathrm{C}$ until reaching mid logarithmic phase (OD of $0.4-0.5$ at $660 \mathrm{~nm}$ ). Cells were then harvested and washed three times in saline. The logarithmic phase cells were transferred to fresh nutrient media $\left(\sim 3 * 10^{3} \mathrm{CFU} / \mathrm{mL}\right)$, microspheres stock solution was added at a final concentration of $50 \mu \mathrm{g} / \mathrm{mL}$ and cells were incubated for $16 \mathrm{~h} / 37^{\circ} \mathrm{C}$, with agitation $(160 \mathrm{rpm})$.

3.4.4. Yeast Cell Survival Assay. The survival rate was calculated by counting the number of colony forming units (CFUs) after appropriate dilution on agar plates, overnight incubation, and calculating the number of colonies per $\mathrm{mL}$. Candida cultures grown without microspheres served as 
control. The reduction percentage in viability was calculated according to the following equation:

$$
\text { Percent change in viability }=-\left(1-\frac{N}{N_{0}}\right) * 100 \text {, }
$$

where $N_{0}$ is the number of CFUs per $\mathrm{mL}$ at time 0 and $N$ is the number of CFUs per $\mathrm{mL}$ in the samples following incubation. All experiments were repeated at least three times.

\section{Conclusions}

In this study, we demonstrate a novel, easy, one-step synthesis of DNA nanospheres coated with bioavailable polymers, PEI and PCL. The DNA nanospheres are able to penetrate the cell directly and are able to express genes inside the cell. This study provides evidence that DNA nanospheres have the possibility of developing as a novel class of medical agents.

\section{Conflict of Interests}

The authors declare that there is no conflict of interests regarding the publication of this paper.

\section{Acknowledgments}

The authors would like to acknowledge Dr. Avi Jacob from the BIU Microscopy unit for his assistance with the image work. The authors also would like to acknowledge Dr. Shay BenAroya for his valuable help and advice regarding the work with yeast cells.

\section{References}

[1] M. Belting, S. Sandgren, and A. Wittrup, "Nuclear delivery of macromolecules: barriers and carriers," Advanced Drug Delivery Reviews, vol. 57, no. 4, pp. 505-527, 2005.

[2] C. M. Wiethoff, J. G. Smith, G. S. Koe, and C. R. Middaugh, "The potential role of proteoglycans in cationic lipid-mediated gene delivery: studies of the interaction of cationic lipid-DNA complexes with model glycosaminoglycans," The Journal of Biological Chemistry, vol. 276, no. 35, pp. 32806-32813, 2001.

[3] M. T. Norcum, "Structural analysis of the high molecular mass aminoacyl-tRNA synthetase complex. Effects of neutral salts and detergents," The Journal of Biological Chemistry, vol. 266, no. 23, pp. $15398-15405,1991$.

[4] R. M. Klein, E. D. Wolf, R. Wu, and J. C. Sanford, "High-velocity microprojectiles for delivering nucleic acids into living cells. 1987," Biotechnology, vol. 24, pp. 384-386, 1992.

[5] M. C. Costanzo and T. D. Fox, "Transformation of yeast by agitation with glass beads," Genetics, vol. 120, no. 3, pp. 667-670, 1988.

[6] O. Yemul and T. Imae, "Synthesis and characterization of poly(ethyleneimine) dendrimers," Colloid and Polymer Science, vol. 286, no. 6-7, pp. 747-752, 2008.

[7] J. Stampfl, A. Wöß, S. Seidler et al., "Water soluble, photocurable resins for rapid prototyping applications," Macromolecular Symposia, vol. 217, no. 1, pp. 99-108, 2004.

[8] O. Boussif, F. Lezoualc'h, M. A. Zanta et al., "A versatile vector for gene and oligonucleotide transfer into cells in culture and in vivo: polyethylenimine," Proceedings of the National Academy of Sciences of the United States of America, vol. 92, no. 16, pp. 72977301, 1995.

[9] Y. Tokiwa, B. P. Calabia, C. U. Ugwu, and S. Aiba, "Biodegradability of plastics," International Journal of Molecular Sciences, vol. 10, no. 9, pp. 3722-3742, 2009.

[10] M. Labet and W. Thielemans, "Synthesis of polycaprolactone: a review," Chemical Society Reviews, vol. 38, no. 12, pp. 3484-3504, 2009.

[11] A. Akinc, M. Thomas, A. M. Klibanov, and R. Langer, "Exploring polyethylenimine-mediated DNA transfection and the proton sponge hypothesis," Journal of Gene Medicine, vol. 7, no. 5, pp. 657-663, 2005.

[12] K. S. Suslick and M. W. Grinstaff, "Protein microencapsulation of nonaqueous liquids," Journal of the American Chemical Society, vol. 112, no. 21, pp. 7807-7809, 1990.

[13] M. D. Bhavsar and M. M. Amiji, "Development of novel biodegradable polymeric nanoparticles-in-microsphere formulation for local plasmid DNA delivery in the gastrointestinal tract," AAPS PharmSciTech, vol. 9, no. 1, pp. 288-294, 2008.

[14] S. Dreis, F. Rothweiler, M. Michaelis, J. Cinatl Jr., J. Kreuter, and K. Langer, "Preparation, characterisation and maintenance of drug efficacy of doxorubicin-loaded human serum albumin (HSA) nanoparticles," International Journal of Pharmaceutics, vol. 341, no. 1-2, pp. 207-214, 2007.

[15] O. Grinberg, A. Gedanken, C. R. Patra, S. Patra, P. Mukherjee, and D. Mukhopadhyay, "Sonochemically prepared BSA microspheres containing Gemcitabine, and their potential application in renal cancer therapeutics," Acta Biomaterialia, vol. 5, no. 8, pp. 3031-3037, 2009.

[16] U. Shimanovich, A. Cavaco-Paulo, Y. Nitzan, and A. Gedanken, "Sonochemical coating of cotton and polyester fabrics with 'antibacterial' BSA and casein spheres,' Chemistry - A European Journal, vol. 18, no. 1, pp. 365-369, 2012.

[17] M. A. Pfaller, D. J. Diekema, G. W. Procop, and M. G. Rinaldi, "Multicenter comparison of the VITEK 2 yeast susceptibility test with the CLSI broth microdilution reference method for testing fluconazole against Candida spp," Journal of Clinical Microbiology, vol. 45, no. 3, pp. 796-802, 2007.

[18] S. Chakraborti, S. Bhattacharya, R. Chowdhury, and P. Chakrabarti, "The molecular basis of inactivation of metronidazole-resistant Helicobacter pylori using polyethyleneimine functionalized zinc oxide nanoparticles," PLoS ONE, vol. 8, no. 8, Article ID e70776, 9 pages, 2013. 

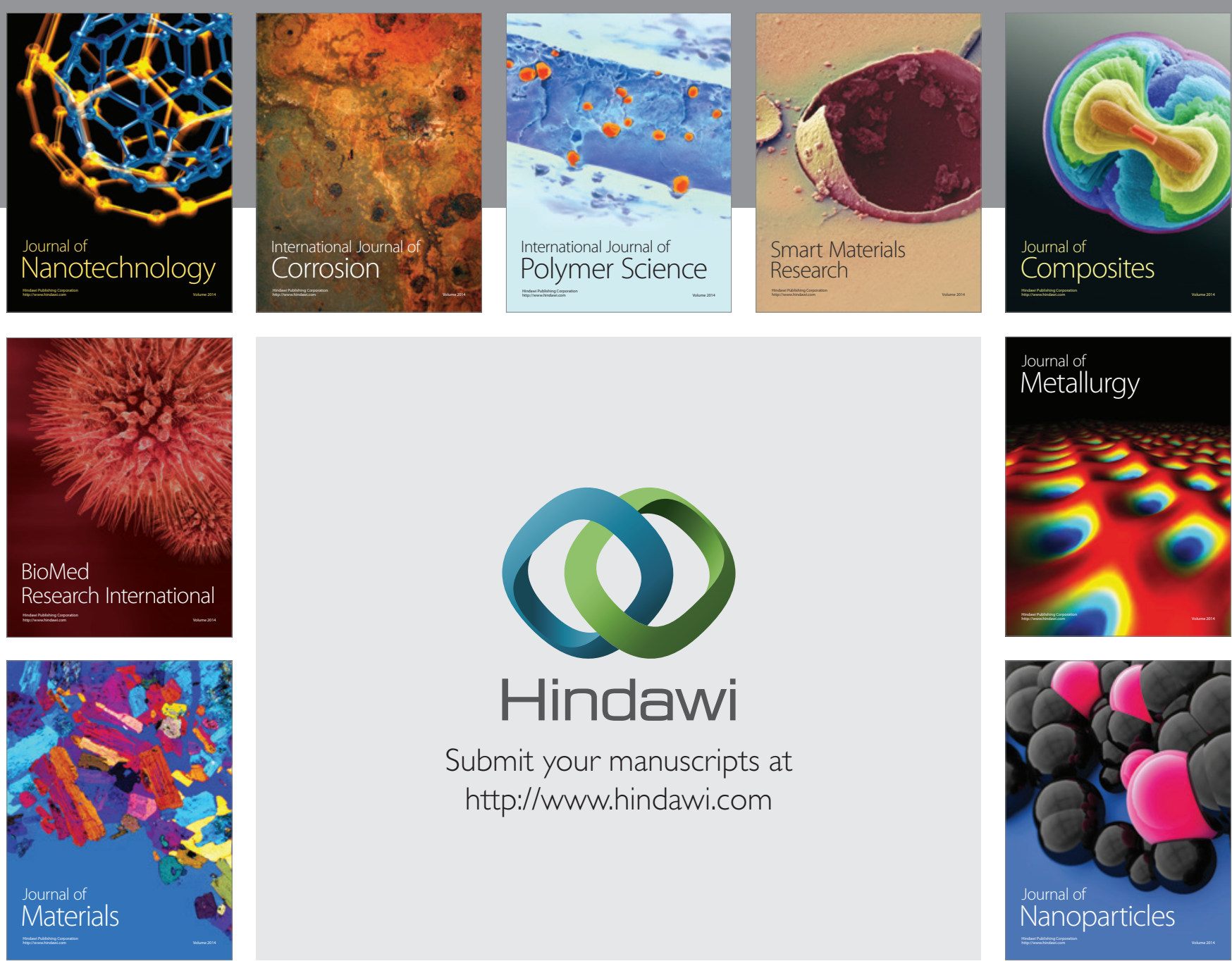

\section{Hindawi}

Submit your manuscripts at

http://www.hindawi.com

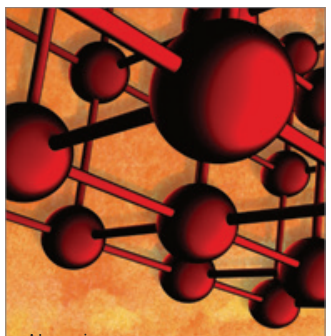

Materials Science and Engineering
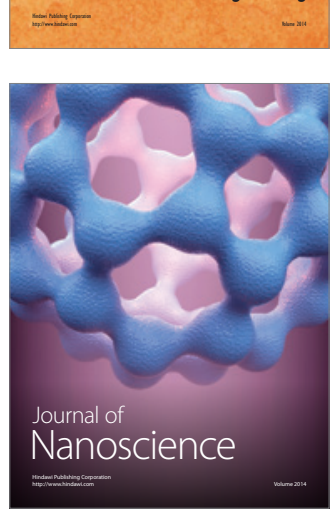
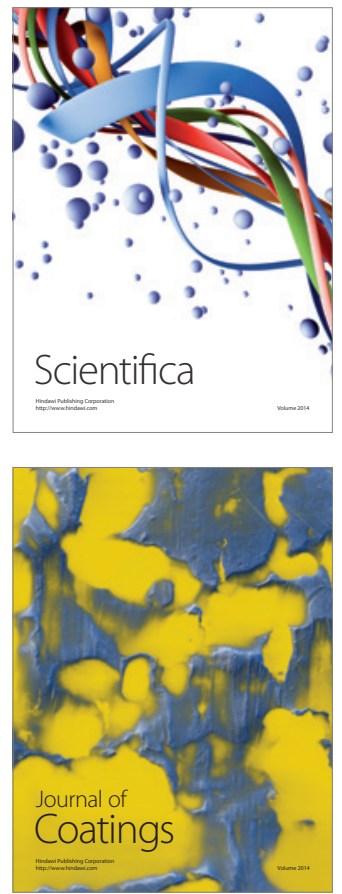
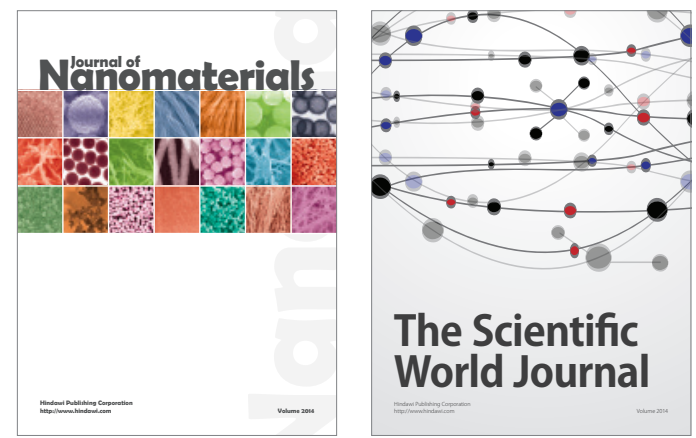

The Scientific World Journal
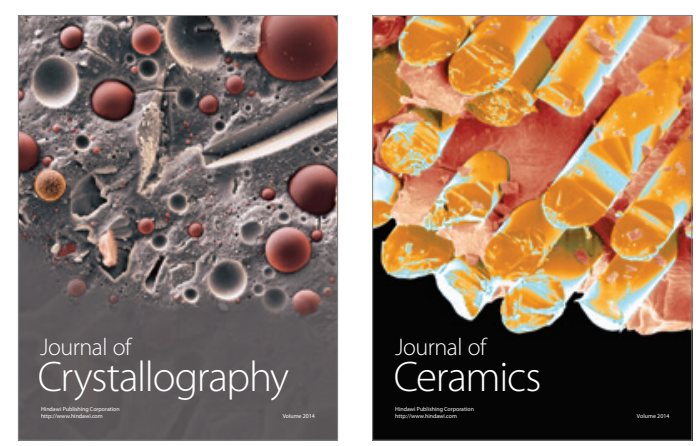
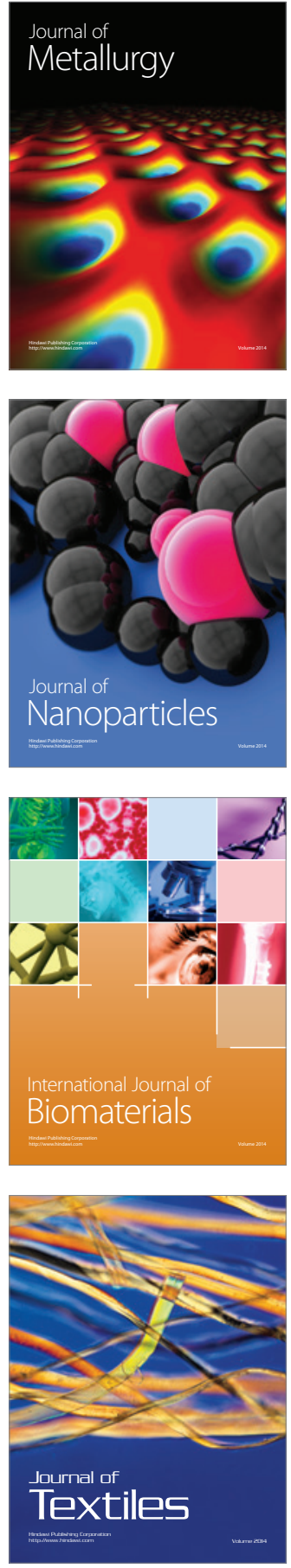